\section{Tropical Journal of Pathology and Microbiology}

\title{
Cutaneous aspergillosis in an immunocompetent patient: a case report
}

\author{
Bagate A. ${ }^{1}$, Birare S. $^{2}$, Jadhav D. ${ }^{3}$, Nalpe V. ${ }^{4}$, Patekar D. ${ }^{\text {* }}$ \\ DOI: https://doi.org/10.17511/jopm.2020.i02.14
}

\author{
${ }^{1}$ A.N. Bagate, Department of Pathology, S.R.T.R. Govt., Medical College, Ambajogai, Maharashtra, India. \\ 2 S.D. Birare, Department of Pathology, S.R.T.R. Govt. Medical College, Ambajogai, Maharashtra, India. \\ 3 D. S. Jadhav, Department of Pathology, S.R.T.R. Govt. Medical College, Ambajogai, Maharashtra, India. \\ ${ }^{4}$ Vinay Nalpe, Department of Pathology, S.R.T.R. Govt. Medical College, Ambajogai, Maharashtra, India. \\ 5* Divya Patekar, Department of Pathology, S.R.T.R. Govt. Medical College, Ambajogai, Maharashtra, India.
}

\begin{abstract}
Cutaneous aspergillosis is a rare disease that is usually seen in immunosuppressed patients. It is rarely found in immunocompetent patients and it is mostly caused by Aspergillus. flavus, Aspergillus fumigatus, and rarely by Aspergillus niger. Cutaneous Aspergillosis is of two types: primary or secondary. Primary cutaneous aspergillosis frequently involves sites of skin injury, at or near intravenous catheter sites, at sites associated with occlusive dressings, at sites of traumatic inoculation, surgery or burns. Secondary cutaneous lesions occur as a result of either from widespread blood-borne seeding of the skin or it may occur from contiguous extension to the skin from an infected underlying structure. The current study is presenting a case of a 25-year-old female, a farmer by occupation, presented with multiple scaly plaques and verrucous nodules with a past history of trauma over knee 3 years back. After trauma she initially noticed lesions over knee followed by the elbow, face and oral lesions noticed 7 months back. There was no present or past history of weight loss, anorexia and serological tests were negative for HIV. One year back she was diagnosed as lupus vulgaris and received Anti-Tubercular treatment without much benefit. She came to our hospital where biopsy from lesions over elbow revealed dense inflammatory exudate, septate fungal hyphae showing acute angle branching on $\mathrm{H}$ and $\mathrm{E}$ stain and PAS stain, which is suggestive of aspergillosis. Scrapping from oral lesion also revealed inflammatory cells with septate fungal hyphae with acute angle branching on PAP stain. Histopathological, cytological study and fungal culture show fungal infection caused by Aspergillus niger.
\end{abstract}

Keywords: Cutaneous aspergillosis, Immunocompetent patient, Aspergillus. Flavus, Immunosuppressed

\section{Corresponding Author}

Divya Patekar, Department of Pathology, S.R.T.R. Govt. Medical College, Ambajogai, Maharashtra, India.

Email: divya7337@gmail.com

\section{How to Cite this Article}

Bagate AN, Birare SD, Jadhav DS, Nalpe V, Patekar D. Cutaneous aspergillosis in an immunocompetent patient: a case report. Trop J Pathol Microbiol. 2020;6(2):204-209.

Available From

https://pathology.medresearch.in/index.php/jopm/ar ticle/view/445
To Browse

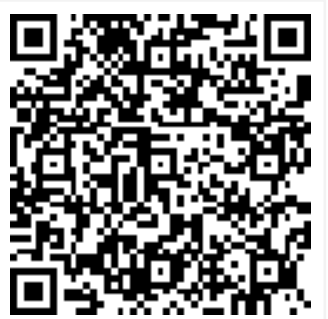

Manuscript Received 28-01-2020

Conflict of Interest No
Review Round 1 04-02-2020

Funding $\mathrm{Nil}$

Review Round 2
08-02-2020
Ethical Approval
Yes

Review Round 3

Accepted 12-02-2020

Plagiarism X-checker $15 \%$

() 2020 by A.N. Bagate, S.D. Birare, D. S. Jadhav, Vinay Nalpe, Divya Patekar and Published by Siddharth Health Research and Social Welfare Society. This is an Open Access article licensed under a Creative Commons Attribution 4.0 International License https://creativecommons.org/licenses/by/4.0/ unported [CC BY 4.0]. 


\section{Introduction}

Opportunistic fungal infection in humans mostly caused by candida Albicans, followed by Aspergillus species. Aspergillosis is a fungal infection found among immunocompromised as well as immunocompetent individuals.

This is primarily pulmonary infection with the involvement of other body sites like paranasal sinuses and cutaneous tissues. Aspergillus species are saprotrophic molds in nature and found in decaying organic matter worldwide. At present, there are 339 species, which are now accepted, and new species continue to be described and added to this list [1].

It may cause some severe infections in immunocompromised patients that result in increased mortality, mainly in neonates [2]. The most common sites of infections are the lungs, sinuses, central nervous system [CNS]. It rarely occurs as a cutaneous infection and is mostly associated with immunodeficiency $[2,3]$.

Aspergillosis is an uncommon opportunistic fungal infection that is caused by a number of species of which Aspergillus fumigatus, Aspergillus niger, and Aspergillus flavus are common ones [4].

In immunocompromised patients, primary cutaneous aspergillosis is usually caused by $A$. flavus and $A$. fumigatus $[4,5]$. A cutaneous aspergillosis is a rare form of a locally invasive lesion that is less commonly associated with Aspergillus niger [4].

It is seen in, immunocompromised patients or those suffering from tuberculosis, silicosis, malignancies, diabetes or patients on long-term corticosteroids or antibiotics. Patients with an organ transplant or chronic granulomatous disease or patients with autoimmune diseases are also at risk. Clinically patients presented with nodules, molluscum-like papules, plaques and ulcers $[1,6]$.

Previous reports have stated that, cutaneous aspergillosis as an either primary or secondary infection. Primary cutaneous aspergillosis can be found in immunocompetent patients. It is very rare but in the last 20 years, there is an increase in prevalence. Primary cutaneous lesions are frequently involving sites of skin injury, at or near intravenous catheter sites, at sites associated with occlusive dressings, at sites of traumatic inoculation, surgery or burns.
Secondary cutaneous lesions occur as a result of either from widespread blood-borne or hematogenous seeding of the skin or it may occur from contiguous extension to the skin from infected underlying structures $[6,7]$. Factors predisposing to this infection include prematurity, antibiotic usage, and maceration [8].

Aspergillosis in man and different animals is primarily confirmed using conventional means of culturing the causative fungal organism from clinical material on standard fungal media such as Sabouraud dextrose agar. Microscopy and culture both in combination increase the diagnostic yield [1].

Histopathological examination of biopsy material stained with hematoxylin and eosin ( $H$ and $E)$, Periodic acid-Schiff (PAS), and other fungal stain show acute angled (-45degree) branching, hyaline septate hyphae with neutrophilic to granulomatous response [1].

\section{Case Report}

A 25-year-old female, the farmer by occupation, presented with multiple scaly plaques and verrucous nodules with a past history of trauma over knee 3 years back. After trauma, she initially noticed lesions over the knee followed by elbow and face (Figure 1).

There was no present or past history of weight loss, anorexia and serological tests were negative for HIV. One year back she was diagnosed as lupus vulgaris and received Anti-Tubercular treatment without much benefit.

She came to our hospital where biopsy from lesions over elbow revealed dense inflammatory exudate, septate fungal hyphae showing acute angle branching on $\mathrm{H}$ and $\mathrm{E}$ stain and PAS stain (Figure 2 and 3 ), which is suggestive of aspergillosis.

She had oral lesion noted 7 months back, scrapping from lesion revealed inflammatory cells with septate fungal hyphae with acute angle branching on PAP stain. (Figure 4) As the patient was having multiple lesions, she was treated with injectable amphotericin B.

This led to the resolution of the inflammation. But after a few months, lesions reappeared and she again started on antifungals, this recurrence may be because of the irregular treatment course.

There was no other associated medical illness, her 
General health remained good during the entire period of follow-up. The patient was found HIV negative, other serological tests were negative, complete blood count and other blood investigation were normal.

As the biopsy from elbow lesion and oral scraping cytology was suggestive of aspergillosis, a sample sent for microbiological examination. $\mathrm{KOH}$ mount revealed fungal elements and on culture revealed Aspergillus niger.

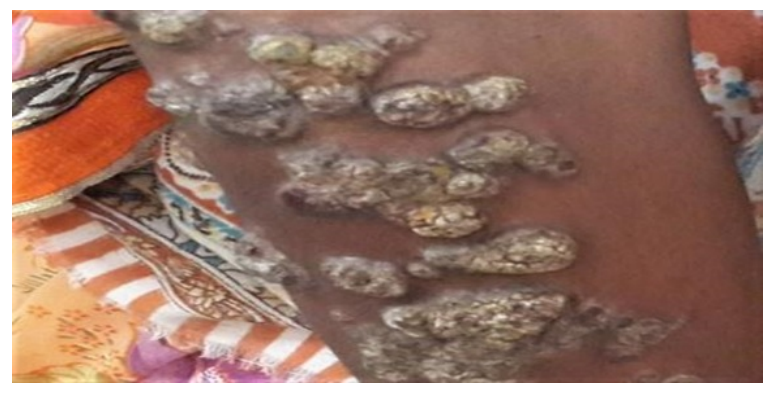

Fig-1: Gross: Scaly plaques with verrucous nodules over right elbow.

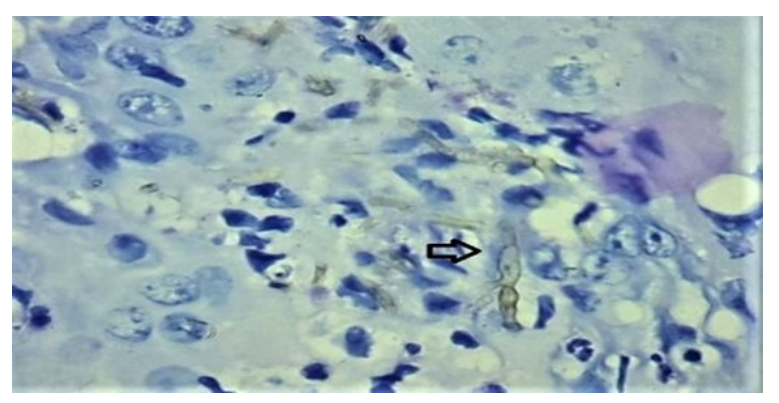

Fig-2: Biopsy from Scaly plaques with verrucous nodules over right elbow shows septate hyphae showing acute angle branching [H and E: 40X].

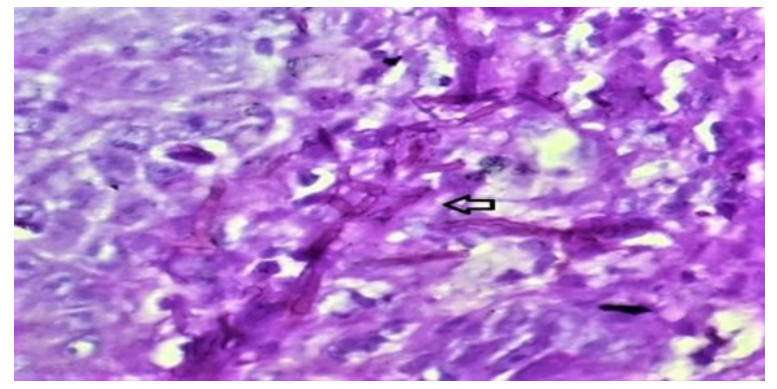

Fig-3: Biopsy from Scaly plaques with verrucous nodules over right elbow shows septate hyphae with acute angle branching [PAS: 40X].

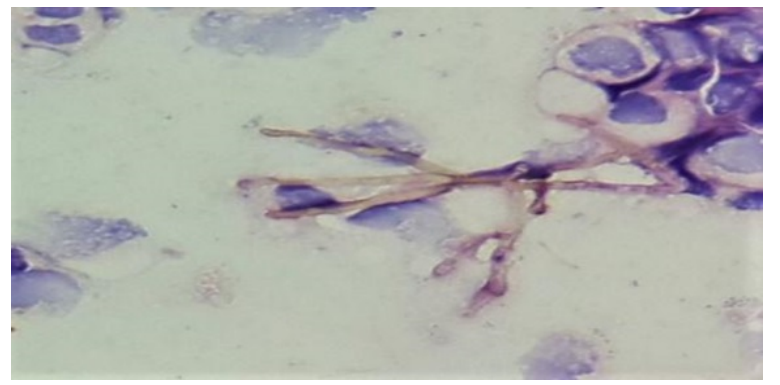

Fig-4: Oral scrapping from mouth ulcer showing septate hyphae with acute angle branching on cytology [PAP: 40X].

\section{Discussion}

Aspergillus species are the most ubiquitous fungi found in decaying vegetations, soil and water [9]. It mostly affects the lungs, naso-orbital area, sinuses, central nervous system, skin and sometimes, it may cause dissemination. It is usually caused by $A$. flavus, $A$. fumigatus, and rarely by $A$. niger.

The condition commonly occurs in immunocompromised states such as severe debilitating illness, uncontrolled diabetes, cancer, burns, and chronic granulomatous diseases or HIV, $[4,10]$ but our patient is not having an immunocompromised status. Cutaneous aspergillosis is a rare disease in immunocompetent patients, therefore, poses a diagnostic challenge [6].

Healthy hosts can develop cutaneous aspergillosis in surgical wounds, traumatic inoculation or by exposure to high spore counts in occupations such as farming $[6,11]$.

In our case patient is a farmer by occupation and was having a history of trauma, which is comparable to study done by Singh Shergill G et al, which shows causative organism is abundant in the environment, most common sources are soil, stored grains, and decaying vegetation, so this appears to be the causative factor in our patient $[12,13,14]$.

Cutaneous aspergillosis is of two types: primary or secondary. Primary cutaneous aspergillosis commonly involves areas or sites of skin injury, near intravenous catheter sites, sites of traumatic or painful inoculation or operated case of any surgery.

Secondary cutaneous lesions usually result either from contiguous extension to the skin from an underlying structure or from widespread bloodborne seeding of the skin from the infected site. 
Clinically, the cutaneous lesions are characterized by macules that may be indurated, papules, plaques or hemorrhagic bullae, which may develop into necrotic ulcers that are covered with a heavy black eschar. Nodules or pustular lesions are rarely occurring. The diagnosis was based on histopathological and mycological examination.

Xess I et al also described the same lesion in an immunocompetent patient due to Aspergillus niger which is comparable to the present study $[4,15]$. Cutaneous aspergillosis is not uncommon in immunocompetent patients [16].

Burik et al found $6 \%$ of lesions caused by $A$. niger in patients not infected with HIV, in the case of the present study patient is negative for HIV tests. [17] Treatment for Aspergillosis is usually with systemic antifungal

Drug therapy like Itraconazole and amphotericin B. Sometimes ketoconazole can be used and Voriconazole has also been newly added to the treatment options [12]. Ajith et al reported a case of cutaneous aspergillosis which showed complete clearance of the lesion with oral itraconazole treatment $[4,18]$.

Treatment had to be changed to intravenous amphotericin $B$, if the lesion worsened or if there was other evidence of clinical failure [4]. In the

Present study as the patient was having multiple lesions, she was on injectable amphotericin $B$. However, in cutaneous disease surgical excision alone or combination with drug therapy was found to be curative [2].

Systemic antifungal drug therapy at least for eight weeks, with attentive clinical observation, effective surgical debridement, local wound care to prevent the spread of infection to adjacent sites.

The wound can be closed after obtaining at least two negative fungal culture results, all these abovementioned factors are likely to increase the rate or chances of successful treatment. After effective surgical debridement and systemic antifungal treatment reduces the chances of recurrence of infection [19].

Early appropriate diagnosis and systemic anti-fungal drug therapy, surgical excision, or a combination of both medical therapy and surgical modalities will improve the outcome, by reducing chances of systemic dissemination and achieving a good cure.
To conclude, the present case report of cutaneous aspergillosis in an immunocompetent patient, farmer by occupation, having a history of trauma. Initially, she was showing response to injectable amphotericin $B$, but these lesions recurred because of irregular treatment. The patient was advised to take regular treatment and report for follow-up.

\section{Reference}

01. Jagdish Chander. Textbook of Medical Mycology. Haryana- Jaype, 4th edition. 2018, page- 524553.

[Crossref]

02. Khatri $M L$, Stefanato $C M$, Benghazeil $M$, Shafi $M$, Kubba A, Bhawan J. Cutaneous and paranasal aspergillosis in an immunocompetent patient. Int J Dermatol. 2000;39(11)853-856.

[Crossref]

03. Tahir C, Garbati M, Nggada HA, Yawe EHT, Abubakar AM. Primary cutaneous aspergillosis in an immunocompetent patient. J Surg Tech Case Rep. 2011;3(2)94-96.

doi: [Article:https://doi.org/10.4103/20068808.92802][Crossref]

04. Granstein RD, First LR, Sober AJ. Primary cutaneous aspergillosis in a premature neonate. Br J Dermatol. 1980;103(6)681-684.

doi: [Article:https://doi.org/10.1111/j.13652133.1980.tb01693.x][Crossref]

05. Xess I, Swetha J, Tanveer N, Asati D, Ramam M, Singh $M$, et al. Primary cutaneous aspergillosis due to Aspergillus niger in an immunocompetent patient. Indian J Med Microbiol. 2009;27(4)367370.

doi: [Article:https://doi.org/10.4103/02550857.55462][Crossref]

06. Chakrabarti A, Gupta V, Biswas G, Kumar B, Sakhuja VK. Primary cutaneous aspergillosisOur experience in 10 years. J Infect. 1998;37(1)24-27.

doi:[Article:https://doi.org/10.1016/S0163-4453(98) 90303-6][Crossref]

07. Sharma S, Yenigalla BM, Naidu SK, Pidakala P. Primary cutaneous aspergillosis due to Aspergillus tamarii in an immunocompetent host. BMJ Case Rep. 2013.

doi: [Article:https://doi.org/10.1136/bcr-2013010128][Crossref] 
08. Chong YS, Ro BI. Cutaneous aspergillosis. Korean J Med Mycol. 2002;7(1)6-13.

doi: [Article:https://doi.org/10.1007/3-540-296689_700][Crossref]

09. Singh SG, Singh T, Neki N, Singh A, Bans Sidhu $P$, Singh Pannu J. cutaneous Aspergillosis in an immunocompetent patient. Int J Med Health Res. 2016;2(12)57-58.

[Crossref]

10. Venugopal $T$, Venugopal $P \quad V$. Primary cutaneous aspergillosis from Tamilnadu diagnosed by fine needle aspiration cytology. Med Mycol Case Rep. 2012;1(1)103-106. doi:

[Article:https://doi.org/10.1016/j.mmcr.2012.09.004 ][Crossref]

11. Xiaoyan Liu, Jun Yang, Weiyuan Ma. Primary cutaneous aspergillosis caused by Aspergillus fumigatus in an immunocompetent patient. Medicine (United States). 2017;96(48)56-59.

doi:

[Article:https://doi.org/10.1097/MD.0000000000008 916][Crossref]

12. Camus M, Anyfantakis V, Dammak A, Riche $A$, Delouane $H$, Roblot $F$, et al. Aspergillose cutanée primitive chez un agriculteur immunocompétent. Ann Dermatol Venereol. 2010;137(5)373-376.

doi:

[Article:https://doi.org/10.1016/j.annder.2010.03.00

6][Crossref]

13. Avkan-Oğuz V, Çelik M, Satoglu IS, Ergon MC, emrah Açan A. Primary Cutaneous Aspergillosis in Immunocompetent Adults- Three Cases and a Review of the Literature. Cureus. 2020;12(1)e6600.

doi: [Article:https://doi.org/10.7759/cureus.6600] [Crossref]

14. Prasad PVS, Babu A, Kaviarasan PK, Anandhi C, Viswanathan P. Primary cutaneous aspergillosis. Indian J Dermatol, Venereol Leprol. 2005;71(2)133-134.

doi: [Article:https://doi.org/10.4103/03786323.14006][Crossref:Crossref]

15. Stevens DA, Kan VL, Judson MA, Morrison VA, Dummer $S$, Denning DW, et al. Practice Guidelines for Diseases Caused by Aspergillus. Clin Infect Dis. 2000;30(4)696-709.

doi: [Article:https://doi.org/10.1086/313756]

[Crossref]
16. van Burik JA, Colven R, Spach DH. Cutaneous aspergillus. J Clin Microbiol. 1998;36(11)31153121.

[Crossref]

17. Romano C, Miracco C. Primary cutaneous aspergillosis in an immunocompetent patient. Mycoses. 2003;46[1-2]56-9.

doi: [Article:https://doi.org/10.1046/j.14390507.2003.00836.x][Crossref]

18. Ajith C, Dogra S, Radotra BD, Chakrabarti A. Primary cutaneous aspergillosis in an immunocompetent individual. J Eur Acad Dermatol Venerol. 2006;20(6)738-739.

doi: [Article:https://doi.org/10.1111/j.14683083.2006.01465.x][Crossref]

19. Woodruff CA, Herbert AA. Neonatal primary cutaneous aspergillosis- Case report and review of the literature. Pediatric Dermatol. 2002;19(5)439-444. doi:[Article:https://doi.org/10.1046/j.1525-1470. 2002.00203.x][Crossref] 